\title{
Scenario Based Regional Water Supply and Demand Model: Saudi Arabia as a Case Study
}

\author{
Abdulaziz A. Alhassan, Alyssa McCluskey, Anas Alfaris, and Kenneth Strzepek
}

\begin{abstract}
Saudi Arabia, although energy rich, is poor in its water resources. The country is part of the arid region where there is no access to any form of fresh surface water. Saudi Arabia resorted to the energy intensive seawater desalination for municipal use to support groundwater resources that is being strand by agricultural activity, putting a significant strain on the country's water-energy-food nexus. This paper uses population and agricultural trends to build futuristic water demand scenarios, and proposes a set of variations on population growth and agricultural policy. The paper matches those demand scenarios to variations of supply scenarios by altering the contribution of desalination. Exploring the effect of these variations on policy options assists in estimating the possible ranges of resources needed, either as groundwater withdrawals or as energy requirements for desalination, enabling decision makers to make better-informed sustainable decisions.
\end{abstract}

Index Terms-Water resources, supply and demand, groundwater, desalination.

\section{INTRODUCTION}

Saudi Arabia is divided into 13 administrative regions; each region has a capital that is usually the largest city in that region. In 2010, the population of Saudi Arabia was 27 million, $65 \%$ of the population lived in the three major regions of Saudi Arabia: Makkah, Riyadh and the Eastern Region [1]. This paper will look into the water balance of Saudi Arabia on the regional level.

The scarcity of rainfall in Saudi Arabia led to the absence of any permanent sources of surface water, forcing Saudi Arabia to rely on two main sources to satisfy water demand: ground water aquifers and seawater desalination. Presently, agricultural demand depends completely on ground water, while industrial and municipal demands are met from a combination of ground water and seawater desalination [2].

Ground water in Saudi Arabia can be described as fossil water. Due to limited rainfall and excessive consumption, the major ground water aquifers are being depleted. A study estimated the storage of the main and secondary aquifers in

Manuscript received October 30, 2014; revised April 28, 2015. This work was supported by King Abdulaziz City for Science and Technology (KACST) Riyadh, Saudi Arabia as part of the Sustainable Infrastructure Planning System (SIPS) conducted by the Center for Complex Engineering Systems (CCES) at KACST and MIT.

A. A. Alhassan and A. F. Alfaris are with the Center for Complex Engineering Systems at KACST and MIT, Riyadh, Saudi Arabia (e-mail: alhassan@mit.edu, anas@mit.edu).

A. McCluskey is with the University of Colorado Boulder, Boulder, Colorado 80309 USA (e-mail: alyssa.mccluskey@ colorado.edu).

K. Strzepek is with the Joint Program on the Science and Policy of Global Change, Massachusetts Institute of Technology, Cambridge, Massachusetts 02139, USA (e-mail: strzepek@mit.edu).
1984 to be around 500 billion cubic meters and a study in 1996 estimated the amount to be 289.1 billion cubic meters [3]. Taking into consideration the reported consumption rates since then, the state of ground water resources in Saudi Arabia is unsustainable [4], and measures should be taken from either demand or supply side (or both) to put the state of water resources in a more sustainable path.

The state of the groundwater is based on limited available data with a large degree of uncertainty. This is due to the fact that estimating exact figures of ground water levels is a difficult and uncertain task. We could end up either overestimating or underestimating ground water levels with a significant margin of error. More studies are needed to better evaluate the current state of ground water levels to make plans that are more reliable for the future. In addition, it is unclear if we are constrained by extraction rates. We do not know if we could reach a point in which extraction rates could be a limiting factor to supply.

Excessive extraction of groundwater is associated with increased financial costs. Lower ground water levels would add more energy demand for extraction from deeper wells. Deeper wells cost more to be dug, and water quality degrades significantly with excessive ground water withdrawal [3], [5].

This paper propose a scenario based regional scenarios where alternations in major demand drivers are proposed, and matched with proposed supply scenario, applying the model to Saudi Arabia as a case study.

\section{Modeling Methodology}

We employ a supply and demand matching mechanism, in which we associate water demand points to supply sources. Each of those has its own characteristics. We use two types of water supply sources:

1) Ground water aquifers: the highest preferred water supply source, each ground water has an estimated storage and a recharge rate

2) Sea water desalination: each desalination plant has a maximum capacity

There are 13 sets of demand points, each set represents one of the 13 regions of Saudi Arabia, and each set has the following type of demand:

1) Municipal Demand: demand consumed by the population for municipal and residential use

2) Agricultural demand: demand for agricultural production, different crop families have different water requirements and different growing cycles, we split agricultural demand into the major crop families

- Cereals: includes wheat, malt and others

- Vegetables: Tomatoes, cucumbers and others 
- Fruits: Dates, Grapes and others

- Fodder: crops used in feeding livestock

\section{A. Scenario Definition}

Each of the two major demand categories: Municipal and Agricultural is associated with a major driver: municipal demand is driven by population while agricultural demand is driven by cultivated land area.

\section{B. Scenario Structure}

For scenario analysis, we use the template in Table I. Each scenario would encompass values of the scenario variable for the thirteen regions of Saudi Arabia. Each scenario would report outcomes described in Table II for each of Saudi Arabia's thirteen regions. For each driver for the two demand categories, we construct three scenarios reflecting a range of low, medium and high growth possibilities.

TABLE I: THE MODEL INPUTS

\begin{tabular}{ll}
\hline \hline Input & Unit \\
\hline Population Projection & Capita \\
Per Capita Water Demand & $\mathrm{m} 3 /$ person/year \\
Desalination Contribution to Municipal Demand & Percent \\
Agricultural Area Projection & Hectare \\
Agriculture Water Intensity & $\mathrm{m} 3 /$ Hectare /year \\
\hline \hline
\end{tabular}

TABLE II: THE MODEL OUTCOMES

\begin{tabular}{ll}
\hline \hline Outcome & Unit \\
\hline Municipal Water Demand & $\mathrm{m}^{3} /$ Year \\
Agricultural Water Demand & $\mathrm{m} 3 /$ Year \\
Ground Water Withdraws & $\mathrm{m} 3 /$ Year \\
Desalination Requirements & $\mathrm{m}^{3} /$ Year \\
\hline \hline
\end{tabular}

\section{WATER DEMAND}

Agricultural water demand constitutes $83 \%$ of the total water demand in Saudi Arabia. The remaining 17\% is municipal and industrial water demand [2]. Fig. 1 shows that both municipal and industrial demand has been increasing steadily, while agricultural demand dipped in 2009 and has been increasing since. Agricultural water supplies are coming from the fossil ground water reserves. The only water costs that farmers bare is the cost of energy needed to pump water from the ground up, and they usually rely on energy resources that are heavily subsidized by the Saudi government [4]. This makes water costs marginal and there is no incentive to invest in water efficient irrigation systems.

\section{WATER DEMAND IN SAUDI ARABIA}

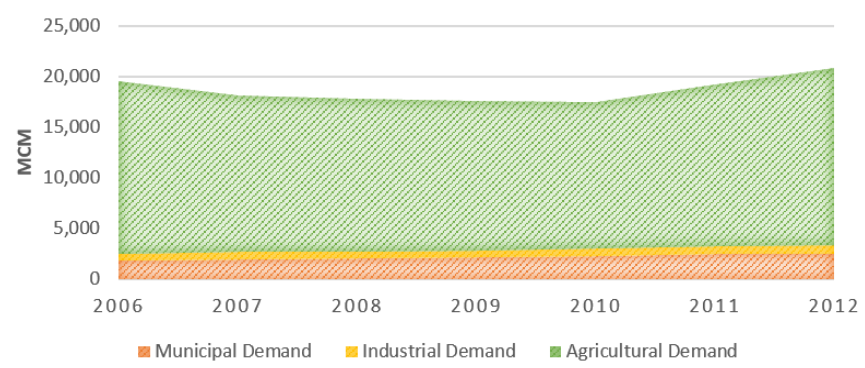

Fig. 1. Historical Agricultural, Industrial and Municipal water demand [2].

Municipal water demand is dependent on seawater desalination. Fifty-five percent of municipal water supplies come from desalination plants that are located on both the east and west coasts of Saudi Arabia [2]. Desalinating seawater is an energy intensive process. The energy requirements of those desalination plants are supplied from the Saudi oil and gas reserves.

\section{A. Municipal Demand}

Municipal water demand in Saudi Arabia is driven by population growth. Population in Saudi Arabia grew significantly in the 1970's and 1980's with growth rates touching $6.5 \%$ due to the jump of quality of life that was associated with the government's oil income. The period of the 1990's and the 2000's exhibited a slower growth rate with a growth rate of around $2 \%$ in 2013 [7].

The last two official censuses $(2004,2010)$ vary with different growth rates across regions. This can be attributed to the fact that some regions are more economically mature than others; causing inter-region migration toward the more economically developed regions. Table III shows the variation of population, and population growth rates across regions.

TABLE III: VARiations of Population, GROWTH, DEMAND AND PER CAPITA Municipal Demand [2], [6]

\begin{tabular}{|c|c|c|c|c|c|c|}
\hline Region & $\begin{array}{l}\text { Population } \\
\text { (2013) }\end{array}$ & $\begin{array}{l}\text { Population } \\
\text { Growth Rate } \\
(2004-2010) \\
\end{array}$ & $\begin{array}{l}\text { Municipal } \\
\text { Demand (2013, } \\
\text { MCM per Year) }\end{array}$ & $\begin{array}{l}\text { Municipal } \\
\text { Demand Growth } \\
\text { Rate (2006-2013) }\end{array}$ & $\begin{array}{l}\text { Contribution of } \\
\text { Desalination } \\
(2013, \%)\end{array}$ & $\begin{array}{c}\text { Per Capita } \\
\text { consumption (2013, } \\
\mathrm{M} \wedge^{\wedge} \text { 3 per Person) }\end{array}$ \\
\hline Saudi Arabia & 30387506 & 3.3 & 2731 & 5.7 & 58 & 90 \\
\hline Riyadh & 7733415 & 3.9 & 808 & 4.6 & 41 & 105 \\
\hline Makkah & 7736211 & 3.3 & 676 & 9.7 & 99 & 87 \\
\hline Madinah & 1972818 & 3.0 & 178 & 4.6 & 85 & 90 \\
\hline Qassim & 1360856 & 3.3 & 120 & 0.7 & 3 & 88 \\
\hline Eastern Region & 4645516 & 3.7 & 599 & 2.9 & 55 & 129 \\
\hline Asir & 2083276 & 2.4 & 76 & 8.2 & 89 & 36 \\
\hline Tabuk & 865861 & 2.5 & 99 & 12.2 & 10 & 114 \\
\hline Hail & 650172 & 2.4 & 32 & 3.5 & 0 & 50 \\
\hline Northern Borders & 350702 & 2.5 & 23 & 15.7 & 0 & 65 \\
\hline Jazan & 1496944 & 2.6 & 38 & 14.5 & 65 & 26 \\
\hline Najran & 567288 & 3.4 & 24 & 14.5 & 0 & 42 \\
\hline Baha & 439697 & 1.7 & 16 & 14.4 & 0 & 37 \\
\hline Jawf & 496401 & 3.6 & 40 & 2.6 & 0 & 81 \\
\hline
\end{tabular}

Regions also varied in their water supply source. Desalination constituted $58.4 \%$ of municipal water supplies. Ninety-nine percent of municipal water supplies in Makkah region came from seawater desalination, where Hail, Northern Borders, Najran, Baha and Jawf regions relied completely on groundwater. Table III shows variation of the 
contribution of desalination across all regions. We can see from Fig. 2. that the contribution of desalination is following an increasing trend.

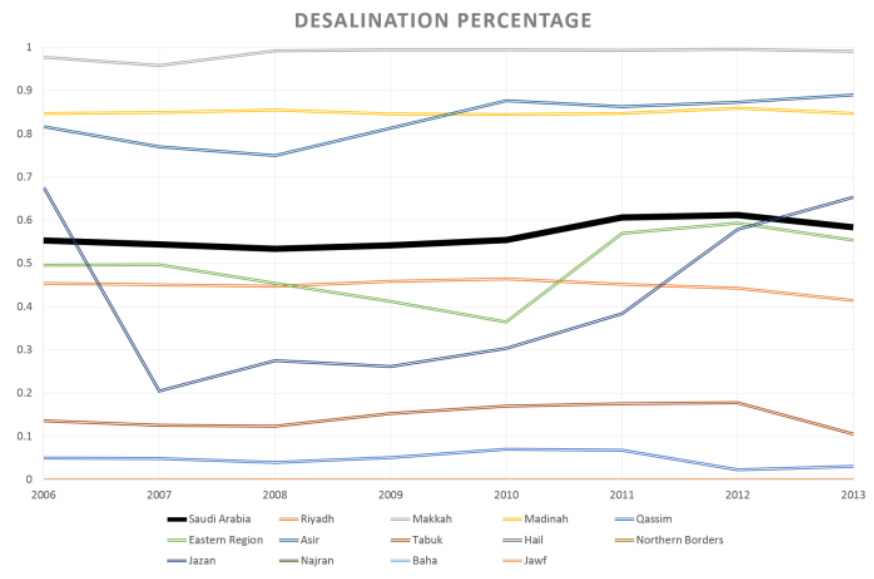

Fig. 2. Historical desalination contribution to municipal demand, by region [8].

Per capita demand is also varying across regions. Table III shows that the Eastern Region is the highest with 129 cubic meter per person per year in 2013, while Jazan per capita consumption was the lowest at 26 cubic meter per capita per year. Fig. 3 shows the steady increase in the national per capita demand, but at the regional level, some regions showed minor decrease, while most regions showed growth in per capita demand.

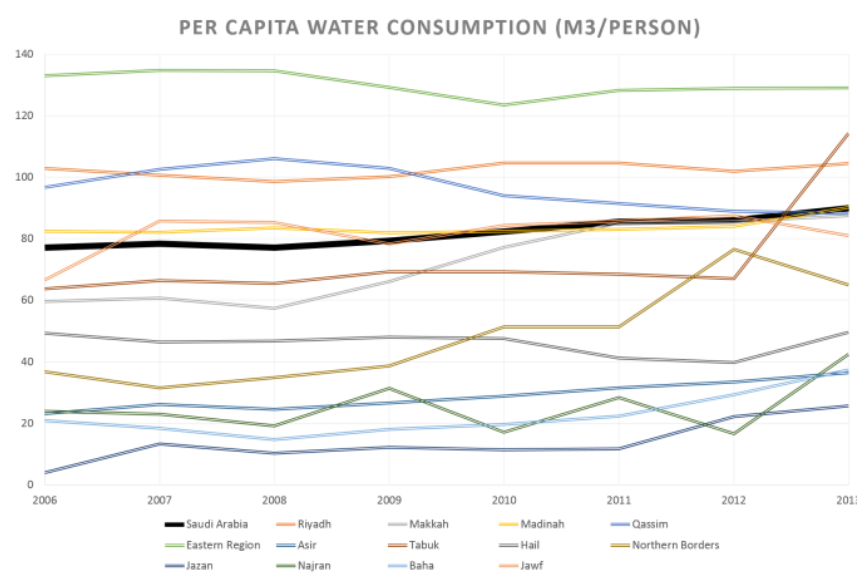

Fig. 3. Historical municipal demand per capita [8].

Municipal demand can be characterized to be seasonally fluctuating, demand rises during summer months, and maximal monthly demand usually falls around July. Demand falls during winter, reaching minimal monthly demand around February. Fig. 4 shows seasonality. The proportion of maximum monthly demand to minimum monthly demand averaged 1.243:1 and the fluctuation of demand is mapped to fluctuation in both supply sources. The proportion of maximum monthly supply to minimum monthly supply averaged 1.239:1 and 1.265:1 for ground water supply and desalinated water supply respectively [8].

Given that population drives municipal demand, we consider three population scenarios, two are from local and international institutions and the third is to study a case of extreme growth in population. Fig. 5 compare those three scenarios.
1) Pop40: The Population Division of the United Nation's Department of economic and social Affair is developing population projections for more than 230 countries and territories. For Saudi Arabia, the UN forecasts 40,387,657 inhabitants in 2050 [7].

2) Pop60: Saudi Arabia's Central Department of Statistics and Information is the institute conducting population censuses, the latest census in 2010 showed that there is 27,563,432 people in Saudi Arabia. To the side of 2010 census, CDSI released its population forecast up to 2025 [6], when extrapolating this forecast up to 2050; Saudi Arabia's population will reach around $60,000,000$ people.

3) Pop65: We develop a third population scenario that project the population to be around $65,000,000$ people in 2050

MONTHLY WATER DEMAND - SAUDI ARABIA

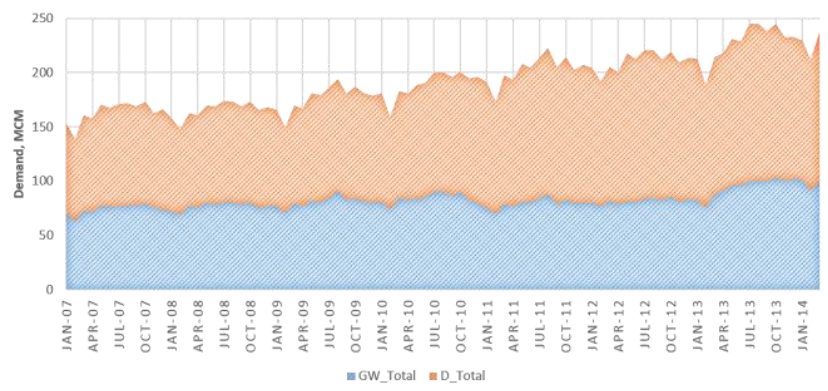

Fig. 4. Historical municipal water demand showing seasonality and contribution of groundwater and desalination, national [8].

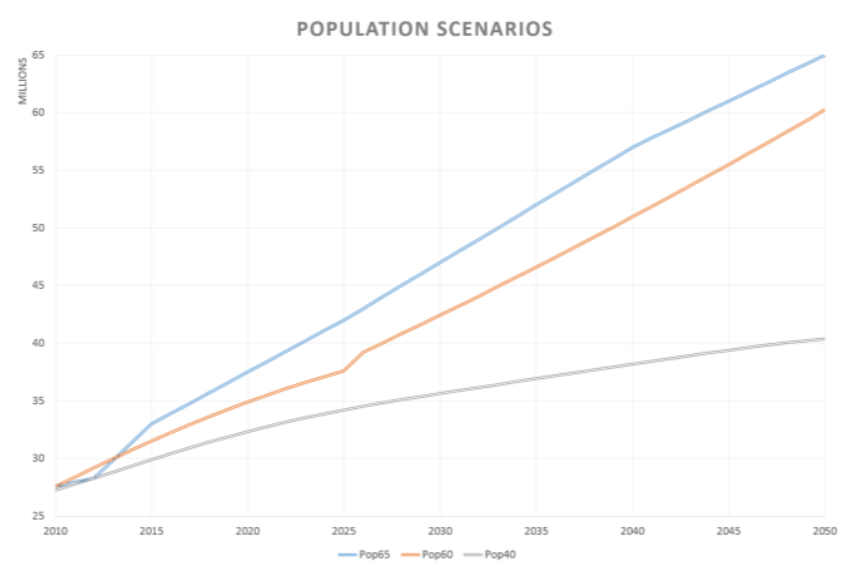

Fig. 5. Three possible population scenarios, after 2010 are projections, national.

Given the three population scenarios, and historical municipal water intensity, it is possible for municipal consumption to increase from its current level in 2013 at 2.7 billion cubic meter a year in 2013 to higher numbers in 2050 . We estimate 3.5 billion cubic meters a year based on Pop40 scenario, 5.3 Billion cubic meter a year based on Pop60 scenario and 5.7 billion cubic meter based on Pop65. Fig. 6 compares projections of regional demand across those three scenarios.

\section{B. Agricultural Demand}

In its effort to diversify its economy, Saudi Arabia initiated a huge agricultural reform initiative, providing interest-free loans to farmers, giving land grants, subsidizing energy, and purchasing certain strategic crops from farmers. This 
government support led to a swift development of the agricultural sector that used to be labor intensive, into a more mechanized and efficient one [9].

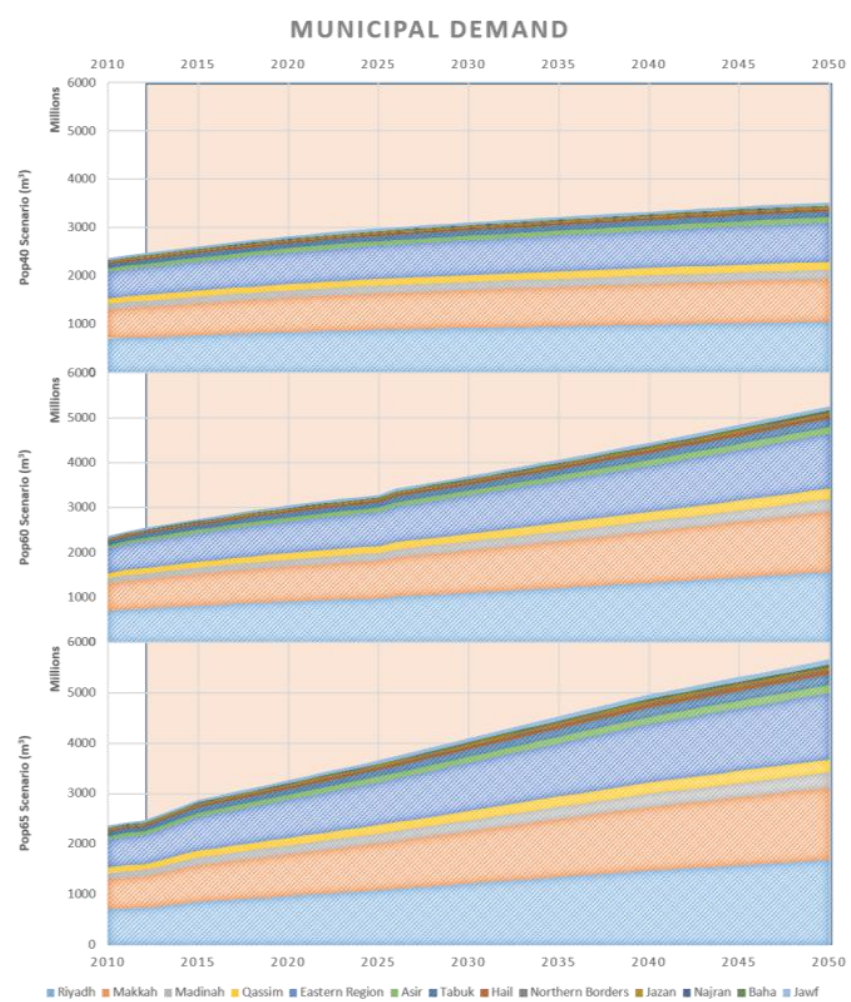

Fig. 6. Three municipal water demand scenarios, after 2013 are projections, regional.

\section{AGRICULTURE AREA (1000 HA)}

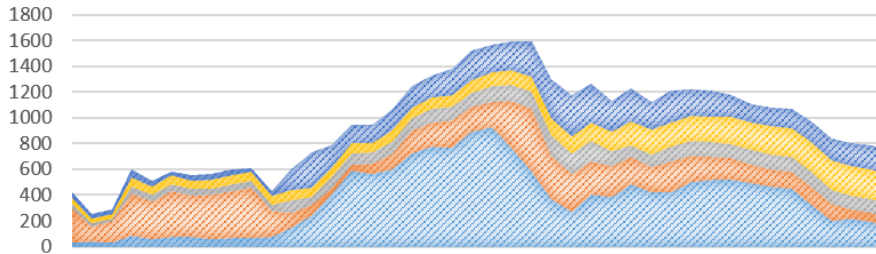

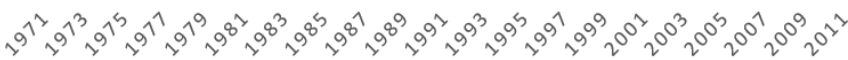

Wheat $\quad$ Other Grains Vegetables Fruits Green Fodder

Fig. 7. Historical agricultural land area showing major crop families, national [10].

Agricultural GDP

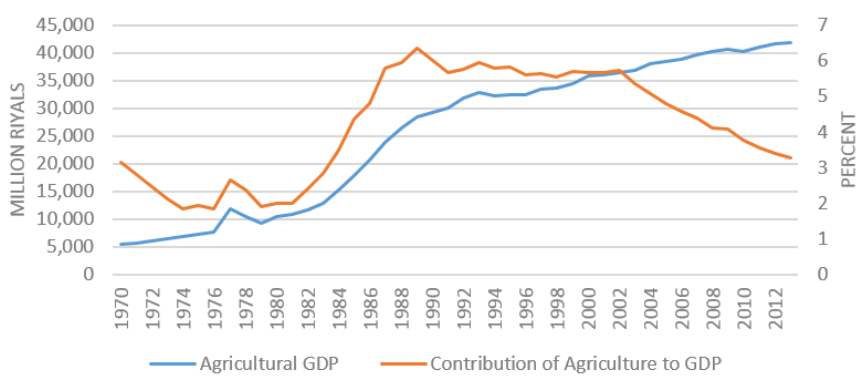

Fig. 8. Agricultural GDP, and contribution of agriculture to overall GDP, national [10].

As seen in Fig. 7, agricultural land area grew from around 400 thousand hectare in 1970 to peak at around 1,600 thousand hectare in the mid 1990's. Since then, agricultural land area has been in a declining trend. In 1970 [10]. It is apparent from Fig. 8 that agriculture contribution to GDP peaked at above $6 \%$ in the late 80 's and 90 's. Agriculture contribution declined steadily in the 2000's until it reached $3 \%$ in 2012 [10]. The steady decline in agriculture's share of GDP is attributed to the higher growth of other components of GDP.

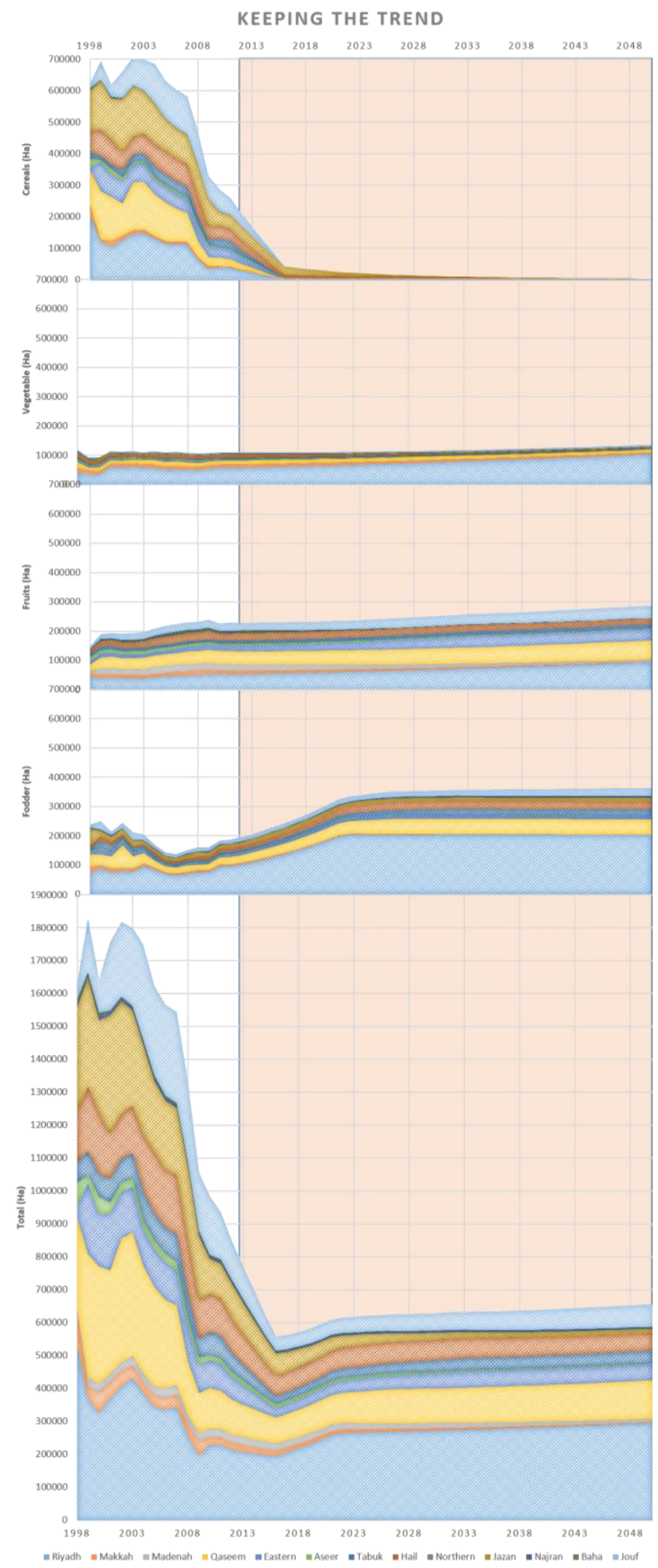

Fig. 9. Projections of agricultural land area based on crop families and regions using keeping the trend scenario.

One of the goals of developing the agricultural sector is to achieve food security. At some point, Saudi Arabia exceeded the point of self-sufficiency and started exporting wheat.

The government acknowledged the severe consequences of the unbound expansion in agriculture on the limited water resources; fossil water being the sole supplier of water for 
agricultural activity is being depleted in faster rates than what was accounted for. In the mid 2000's, the government started regulating agriculture, limiting the number of new water well permits, banning the exportation of fodder, stopping permits to grow fodder, and shutting down its wheat purchasing program in an eight year process, reducing its purchases by $12.5 \%$ annually to stop purchasing wheat in 2015 [9].

We assume three scenarios of agricultural land area; all of those scenarios take into consideration the shutdown of wheat growing:

\section{1) Keeping the trend}

After shutting down the wheat-growing program, new dynamics appeared in the agricultural horizon, expansion in growing fodder was one result. This scenario keeps the growth (or decline) trend exhibited in the period of 2008-2012 which followed wheat shutdown.

\section{2) Keeping constant}

Keeping agricultural land area constant as of 2012 numbers.

\section{3) Linear shutdown}

We study the effect of shutting down agriculture by 2040 , given the current government policy on restricting agricultural activity, and the fact that ground water is being depleted by agriculture, make this scenario a plausible option.

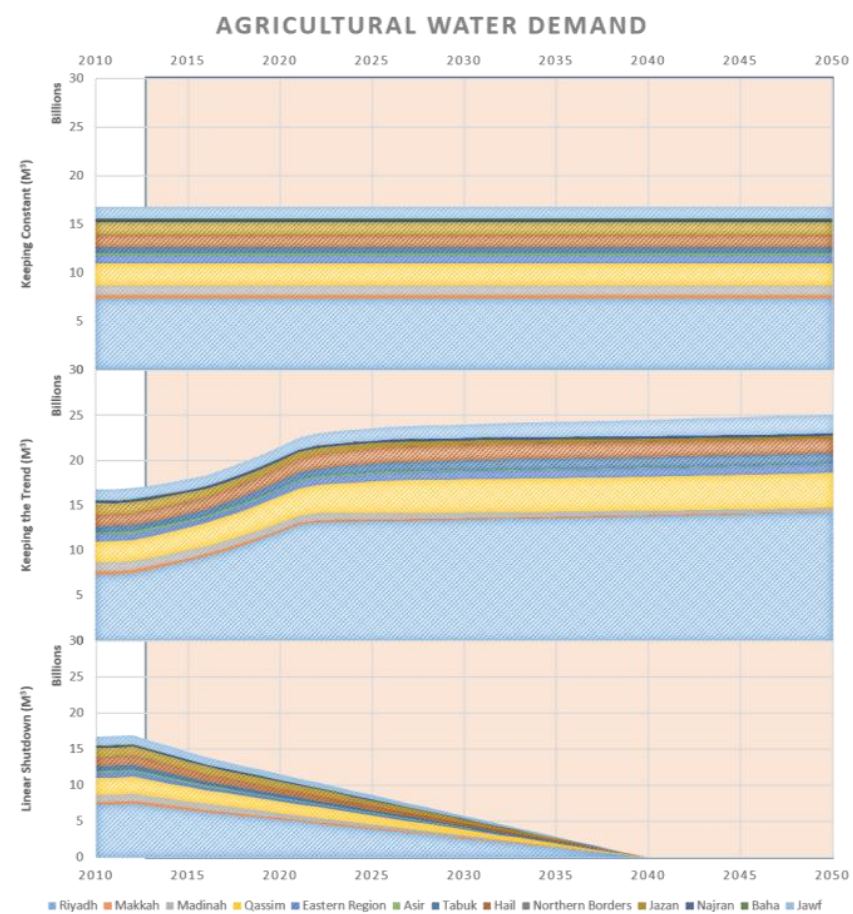

Fig. 10. Agricultural water demand based on three scenarios, regional.

The government's decision to stop purchasing wheat, led farmers to seek other alternative crops. Fodder, being in high demand in the livestock and dairy industries was an economically sound choice for farmers. Fig. 9 indicates that if the trend kept going for a reasonably short amount of time, the wheat growing activity would reach zero as was anticipated by the policy target year, but the fodder cultivated areas would grow to replace most of what wheat was occupying. Given that fodder is grown all year round, and it is more water-intense than wheat, this would lead to higher water demand. Although Keeping the Trend scenario exhibits a period of decline in cultivated areas, that decline is matched with increasing water consumption mainly because of the shift to fodder. Fig. 10 compares those three scenarios in terms of water consumption. Keeping Constant scenario would hold agricultural water consumption constant at its current levels, and Linear Shutdown would lead to zero consumption levels by the arbitrarily defined year 2040. What is worth looking at is the Keeping the Trend scenario as it largely reflect an effect of a policy change.

\section{WATER SUPPLY}

While Agricultural demand is met completely by groundwater, municipal demand is met via a combination of groundwater and seawater desalination. Based on the demand analysis above, we propose three scenarios on desalination contribution to municipal demand:

\section{A. Constant Capacity}

Where we assume there is no further expansion of the existing desalination infrastructure, and assuming that 2013 desalination capacity would remain fixed.

\section{B. Constant Contribution}

Where we assume that desalination contribution percentage would remain fixed at its 2013 levels. Desalination would grow/decline to cover the same percentage that it was covering in each region.

\section{Growing Desalination}

Where we assume that desalination would supply hundred percent of demand in coastal regions (Makkah, Madinah, Eastern Region, Asir, Tabuk and Jazan) in addition to Riyadh region, which already receive majority of its supplies from seawater desalination.

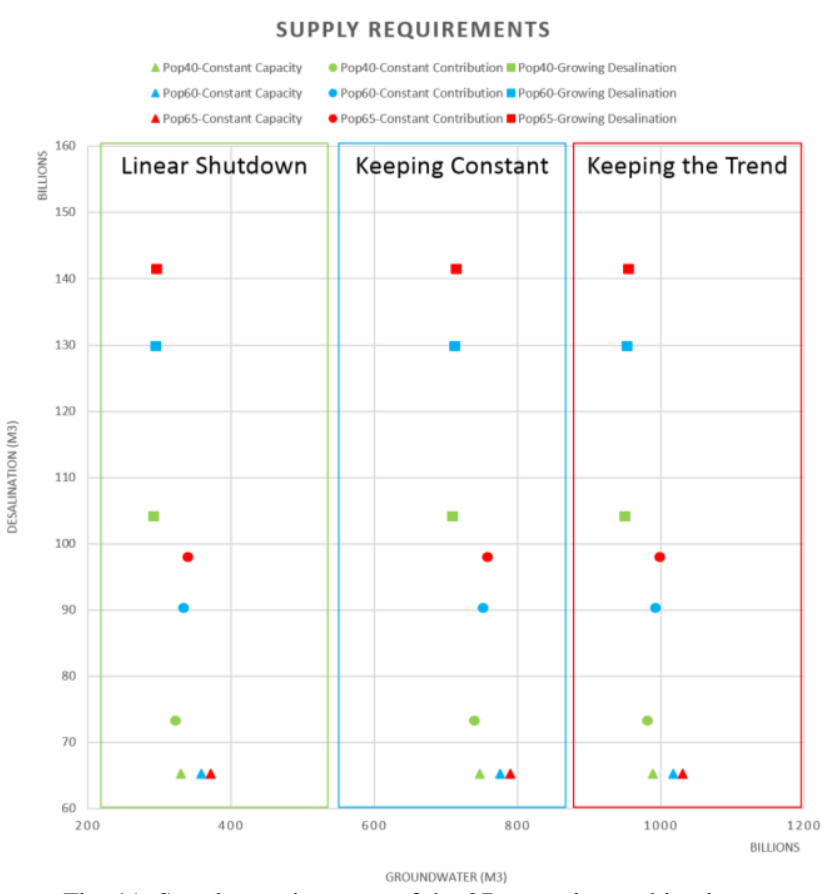

Fig. 11. Supply requirements of the 27 scenario combinations.

Fig. 11 shows the total supply requirements in the period from 2010 to 2050 for all the combinations of the following scenarios: 
- Population Scenarios (Pop65, Pop60 and Pop40

- Agricultural Scenarios (Keeping the Trend, Keeping Constant and Linear Shutdown)

- Desalination Scenarios (Constant Capacity, Constant Contribution and Growing Capacity)

The amount of groundwater withdrawals over the period ranged between 290 billion cubic meters and 1030 billion cubic meters. The variation is mainly related to the agricultural scenario component. Seawater desalination requirements for the period of 2010 to 2050 are estimated to vary between 65 billion cubic meter and 141 billion cubic meters. This variation is linked to both variations in the population scenarios and desalination scenarios.

\section{CONCLUSION}

In this paper, we described a scenario based regional water supply and demand model in which we proposed three scenarios on population as a driver for municipal use, and three scenarios on agricultural land area as a driver for agricultural demand, and we introduced three scenarios on supply breakdown.

The large effect of agriculture on groundwater withdrawals is significant. The need to extract 290 Billion cubic meters of groundwater needed in the most conservative scenario is significant by itself. Let alone the worst-case scenario of 1030 billion cubic meter in the most extreme scenario. [3] Shows estimates of groundwater reserves of only 289 Billion at 1996, but consumption in the period of 1996-2013 proved that estimate wrong. It is obvious that there is a need for more detailed understanding of the state of groundwater to make well-informed decisions. Detailed understanding of the state of ground water would enable Saudi Arabia to better plan its seawater desalination infrastructure, where and how large the next desalination investment should be is totally dependent on our knowledge of the availability of groundwater resources. Demand side measures should be taken as well, the excessive groundwater withdraws for agriculture would lower groundwater levels and degrade quality, leading to more energy requirements to deliver groundwater to demand points. Reforming agriculture by taking actions to determine what crops are the most suitable for Saudi Arabia's water balance, and determining the amount of cultivated land area, and using more efficient irrigation methods are among the candidates for policy reform. Experimenting with unconventional agriculture is an option, for instance, indoor hydroponic agriculture using LED as a substitute for sunlight is claimed to save $90 \%$ of water requirements in agriculture.

\section{REFERENCES}

[1] Preliminary Results of the 2010 Census, Central Department of Statistics and Information (CDSI), Riyadh, Saudi Arabia, 2010.

[2] 2013 Annual Report, Ministry of Water and Electricity (MoWE), Riyadh, Saudi Arabia, 2014.

[3] H. M. H. Al-Sheikh, "Country case study - Water policy reform in Saudi Arabia," presented at the Second Expert Consultation on National Water Policy Reform, 1997, pp. 1-20.

[4] Groundwater Management in Saudi Arabia, Food and Agriculture Organization of the United Nations, Rome, Italy, 2009.

[5] B. L. Morris, A. R. Lawrence, P. J. Chilton, B. Adams, R. C. Calow, and B. A. Klinck, "Groundwater and its susceptibility to degradation: A global assessment of the problem and options for management," Early Warning and Assessment Report Series, RS. 03-3, United Nations Environment Programme, Nairobi, Kenya, 2003.

[6] Midyear Population Estimates: Regional Level for 2010-2025, Central Department of Statistics and Information (CDSI), Riyadh, Saudi Arabia, 2010.

[7] World Population Prospects: The 2012 Revision, United Nations Department of Economic and Social Affairs.

[8] Water Resources System. Ministry of Water and Electricity (MoWE). [Online]. Available: http://app.mowe.gov.sa/ipspublic/

[9] Ninth Development Plan: Chapter 28: Agriculture, Ministry of Economy and Planning, Riyadh, Saudi Arabia, 2010.

[10] Annual Statistics Book, Saudi Arabian Monetory Agency (SAMA), Riyadh, Saudi Arabia, 2013.

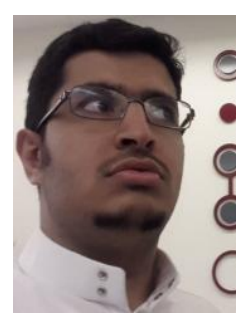

Abdulaziz A. Alhassan is a research specialist at the Center for Complex Engineering Systems (CCES) in King Abdulaziz City for Science and Technology (KACST) and Massachusetts Institute of Technology (MIT). Abdulaziz holds a bachelor degree in computer science from King Fahd University of Petroleum and Minerals (KFUPM). Abdulaziz's focus was on machine learning and data mining. He has a minor in economics. At CCES, Abdulaziz worked to develop decision-making tools based on scientific modeling and data analysis. Abdulaziz's fields of interests cover a spectrum of topics including water and energy economics, economy of labor market, city planning, human dynamics and public transportation. $\mathrm{He}$ has a comprehensive understanding of these topics in the context of Saudi Arabia. 